\title{
Argyria mimicking a blue nevis: dermoscopy features ${ }^{*}$ Argíria imitando um nevo azul: características dermatoscópicas
}

\author{
Maria Leonor Enei ${ }^{1}$ \\ Francisco Macedo Paschoal ${ }^{2}$
}

Rodrigo Valdés ${ }^{3}$

http://dx.doi.org/10.1590/abd1806-4841.20132022

\begin{abstract}
Argyria is a rare disease caused by prolonged skin contact with silver. Localized cases have been described regarding the use of topical medications, and trauma with objects containing this metal such as acupuncture needles and jewelry. Clinically, a macule or a patch, round or oval, appears in the infected area, with a characteristic bluey-gray color. To our knowledge this is the first time that this clinical condition has been described through the use of dermoscopy.
\end{abstract}

Keywords: Argyria; Dermoscopy; Nevus, blue

Resumo: A argíria é uma doença rara, causada pelo contato prolongado da pele com prata. Foram descritos casos localizados relacionados ao uso de medicamentos tópicos e traumas com objetos que contem esse metal, como agulhas de acupuntura e jóias, por exemplo. Clinicamente, aparecem máculas ou manchas redondas ou ovais na área afetada, com uma característica cor azul-acinzentada. Até onde sabemos esta é a primeira vez que este quadro clínico foi descrito através da dermatoscopia.

Palavras-chave: Argíria; Dermatoscopia; Nevo azul

\section{INTRODUCTION}

Argyria is an uncommon clinical condition induced by prolonged skin exposure to silver. Two known types of argyria exist: localized and generalized. Localized argyria has been reported as the result of the use of topical medication and the inadvertent implanting in the skin of objects that contain silver. ${ }^{1,2}$ Clinically, this type of argyria is characterized by the appearance of blue-gray macules in skin areas near to the objects implanted. This condition is generally diagnosed by histopathology, although in certain cases it may be necessary to identify the presence of the metal by electron microscopy. ${ }^{2,3}$ In the present case report, we describe a patient who developed localized argyria caused by the implantation of a silver earring in the right ear. Clinically, the presentation was similar to that of a blue nevus. Three reported cases have emerged in which a silver earring was associated with skin discoloration. To the best of our knowledge, the case described below is the first for which dermoscopy has been used to diagnose argyria. ${ }^{4,5}$

\section{CASE REPORT}

A 30-year-old female patient was referred with asymptomatic induration of the right ear lobule. The posterior region of this area of skin presented a 10-mm oval-shaped macule with an intense steel-blue coloration, under which a small nodule was palpable (Figure 1). The patient remembered experiencing a pre-

Received on 29.07.2012.

Approved by the Advisory Board and accepted for publication on 10.09.2012.

* Study was conducted at the above private clinic in Iquique, Chile.

Conflict of interest: None

Financial funding: None

Specialist in Dermatology, certified by the Brazilian Society of Dermatology. Private practice in Iquique, Chile.

Assistant Professor of Dermatology - Faculty of Medicine of the ABC (FMABC) - São Paulo (SP), Brazil.

Specialist in histopathology - Institute of Histopathology, Histonor - Antofagasta, Chile.

(C)2013 by Anais Brasileiros de Dermatologia 

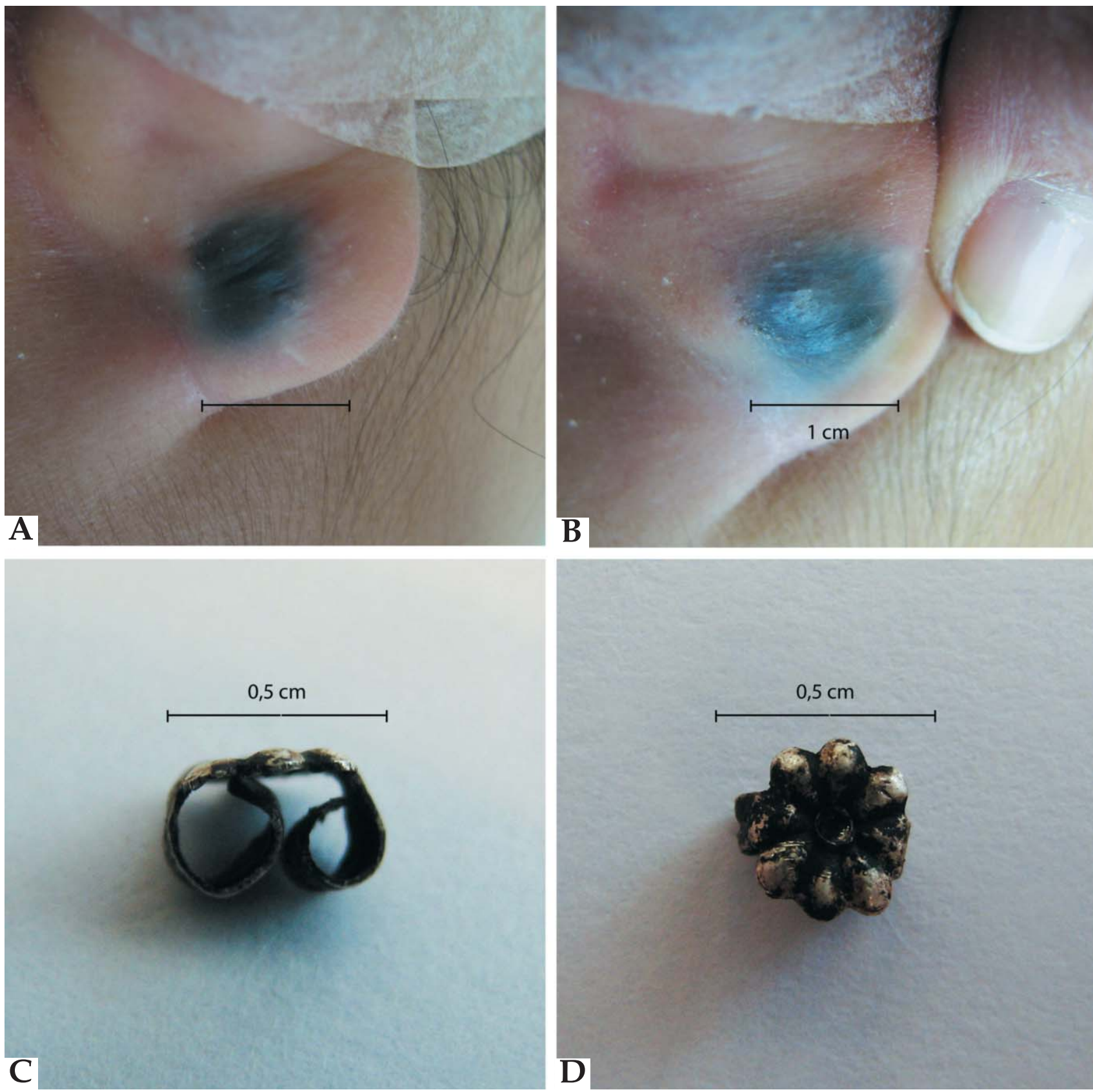

FIGURE 1: (a) Steel-blue oval-shaped macule behind the right ear lobule. (b) small nodule was palpable under the macule (c-d) metallic piece that belonged to a silver earring was removed from the lobule

vious local inflammatory episode generated by a silver earring 25 years ago. Dermoscopy examination of the macule revealed an area comprising blue-grey structures uniformly distributed across a yellow background (Figure 2A). The lesion was composed of the following three structural types: annular structures, short linear structures observed between the former structures, and multiple dots. The distribution of the lesions was homogeneous and of a parallel aspect (Figure 2B). A white area with a radiated aspect was clearly visible in the center of the lesion (Figure 2A). We performed a cutaneous biopsy of the more indurated area and extracted a metallic piece belonging to a silver earring (Figure 1). The histopathological study revealed the presence of brown-pigmented granules that had accumulated inside the dermic papillae and densely populated the interpapillary dermis over the elastic fibers and vessel walls surrounding the eccrine glands (Figure 3). 

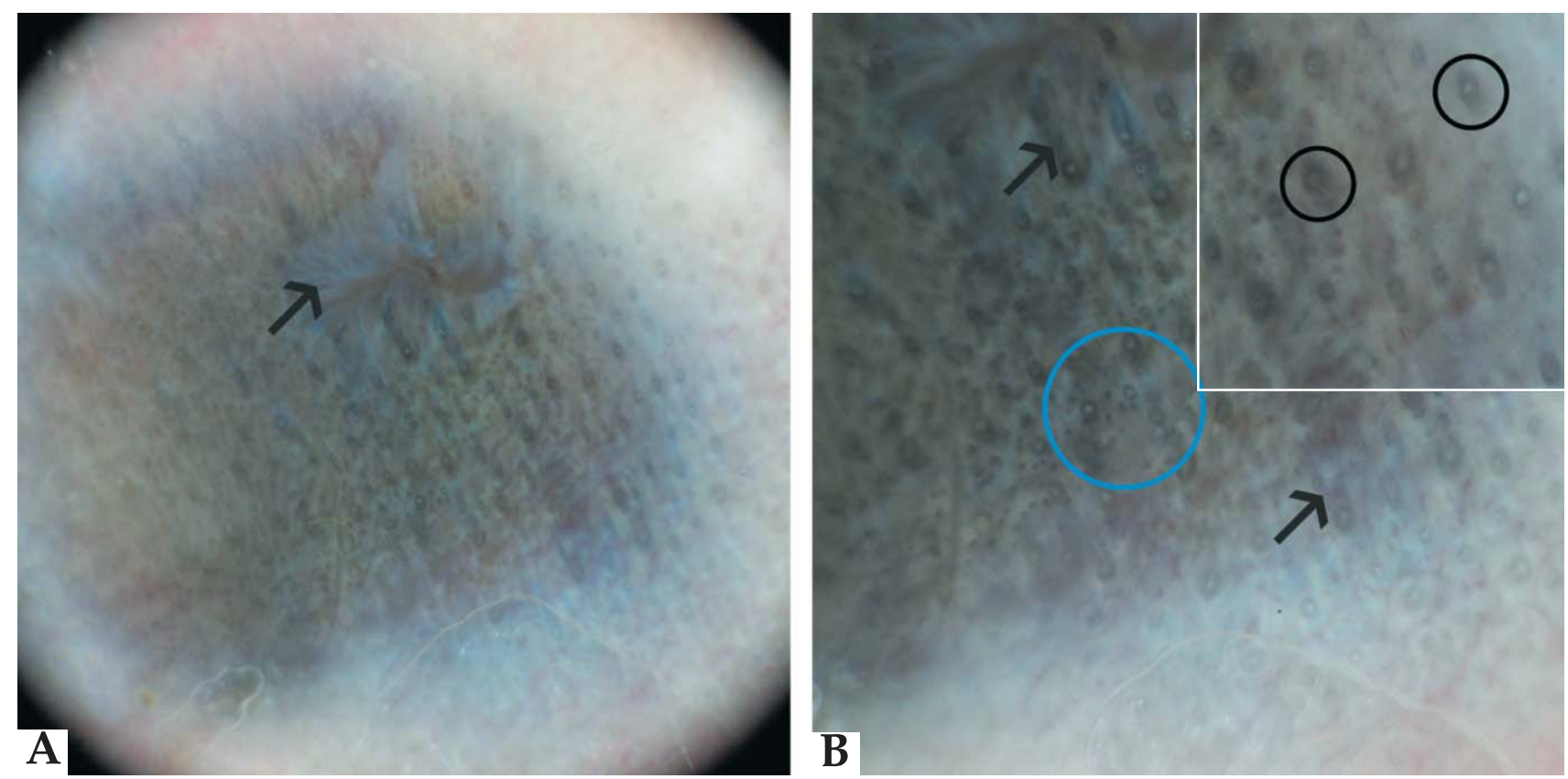

FIGURE 2: (a) Dermoscopy (10x): area composed of blue-grey structures across a yellow background. In the middle of the lesion there was an area with a radiated aspect corresponded to scar fibrosis caused by the earring. (b) Dermoscopy (40x): three types of dermoscopic structures existed: annular structures (black circles), short linear structures (arrows) and multiple spots (blue circle)
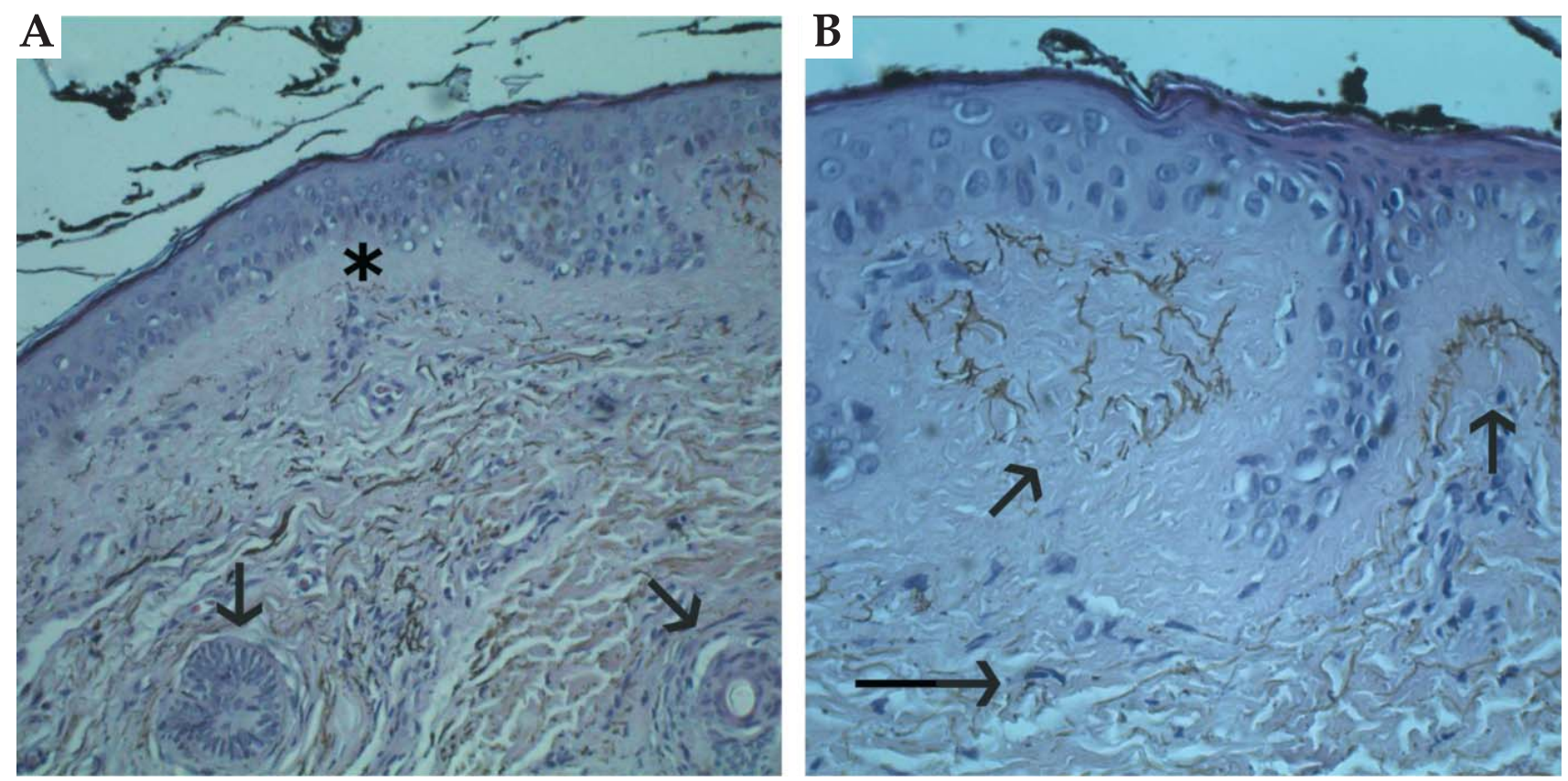

FIGURE 3: (a) Histopathology(100x): brown-pigmented granules surrounding the eccrine glands (arrows). The pigment was localized under a Grenz zone (asterisk) (b) Histopathology (200x): brown-pigmented granules were inside the dermic papillae (short arrows) and densely populated the interpapillary dermis over the elastic fibres and vessel walls (long arrows)

\section{DISCUSSION}

The discoloration commonly observed in cases of argyria is not the result of a local inflammatory or allergic reaction, but rather the deposition of silver sulphide and selenide, which are both produced by the oxidation of soluble compounds in tissues. ${ }^{4}$ These com- pounds are deposited following slow tissue flux and are captured by elastic fibers and the basement membrane before reaching the epithelium. If we correlate the dermatologic and histological findings, the dots, the annular structures, and the short linear structures 
correspond to the pigment localized in the papillae, the pigment surrounding the eccrine glands, and the pigment following the elastic fibers into the interpapillary dermis, respectively. The blue-grey color of the dermoscopy structures was most probably produced via a refringence phenomenon (Tyndall effect), which gives the appearance of a brown pigment that is located deep within the dermis. In addition, the yellow color at the back of the lesion was observed due to the presence of the Grenz zone, under which the pigment was localized, and the white area with a radiated aspect corresponded to scar fibrosis caused by the earring.

Differential diagnosis should be performed primarily for lesions such as blue nevi, deep intradermic nevi, and metastatic melanoma. In our case, however, none of the dermoscopy criteria for melanocytic lesions, such as the presence of a homogeneous blue area, aggregated globules, red pigment or streaks, were present. Importantly, the use of dermoscopy enabled the observation of annular structures in lentigo solaris, malignant lentigo and ochronosis. ${ }^{6}$ In contrast to these lesions, the pigment deposition in argyria surrounds the eccrine glands rather than the follicle openings. Furthermore, the clinical manifestations of other skin disorders present additional dermoscopy structures that can serve to differentiate these lesions from those associated with localized argyria. Finally, dermoscopy analysis of a tattoo can reveal the presence of multiple spots without a specific pattern, which correlate with the pigment or metal that is phagocytized by dermal macrophages following the local dermal inflammation produced by the tattooing process.

In conclusion, localized argyria is benign but irreversible and is not associated with systemic disorders or the development of malignancy. Its identification, however, is clinically relevant because this condition can simulate melanocytic proliferation. The present case report aimed to discuss the dermoscopy characteristics that can be used to facilitate the identification of localized argyria.

\section{REFERENCES}

1. Flohr C, Heague J, Leach I, English J. Topical silver sulfadiazine-induced systemic argyria in a patient with severe generalized dystrophic epidermolysis bullosa. $\mathrm{Br} \mathrm{J}$ Dermatol. 2008;159:740-1.

2. Hristov AC, High WA, Golitz LE. Localized cutaneous argyria. J Am Acad Dermatol. 2011;65:660-1.

3. Matsumara T, Kumakiri M, Ohkawara A, Himeno H, Numata T, Adachi R. Detection of silenium in generalized and localized argyria:report of four cases with X-ray microanalysis. J Dermatol. 1992;19:87-93.

4. Sugden $\mathrm{P}$, Azad S, Erdmann M. Argyria caused by an earring. $\mathrm{Br} \mathrm{J}$ of Plastic Surgery. 2001;54:252-3.

5. Shall L, Stevens A, Millard LG. An unusual case of acquired localized argyria. $\mathrm{Br} \mathrm{J}$ Dermatol. 1990;123:403-7.

6. Pereira P, Mariano A, Francesconi F, Francesconi V, Romero S. Use of dermoscopy for diagnosis of exogenous ochronosis. An Bras Dermatol. 2011;86:S31-4.

\author{
MAILING ADDRESS: \\ Maria Leonor Enei \\ Santiago Polanco $2030102^{\circ}$ Piso I. \\ Iquique 1100000 \\ Chile \\ E-mail:leonorenei@vtr.net
}

How to cite this article: Enei ML, Valdés R, Paschoal FM. Argyria mimicking a blue nevis: dermoscopy features. An Bras Dermatol. 2013;88(3):452-5. 